\title{
Hyo-Kyu Kim (1917-1999): The One Who Constructed Gangnam Severance Hospital and Reformed Yonsei University Health System
}

\author{
Byung Soo Kim \\ Emeritus Professor, Yonsei University College of Medicine, Seoul, Korea.
}

It has been almost half a century since I started working for Yonsei University Health System. I have come to write this to testify the great roles that our teachers played to ensure that Yonsei University Health System could achieve the advancements that it is enjoying today.

Yesterday, I visited the mortuary of former Prime Minister Duck-woo Nam to express my condolences. While I stayed there for almost 3 hours, I met many people. Prime Minister Duck-woo Nam greatly contributed to the modernization and economic development of our country as a Minister of Finance (1964-1974) and a Deputy Prime Minister of Economy Planning Board (EPB; 1974-1978) of President Chung-hee Park's administration (1961-1979). One of the issues at the time was the return of nurses that our country had dispatched to Germany. Our government came up with countermeasures at the request of the German government. Then Prime Minister Kyu-hah Choi (1975-1979), who had been at Kyunggi Middle School together with Dr. Hyo-Kyu Kim (Fig. 1), recommended Deputy Prime Minister of Economy Planning Board Duck-woo Nam to meet with Dr. Hyo-Kyu Kim, who was in charge of Yonsei University Health System and had various experiences in medical administration, to discuss the matter. At first, Dr. Hyo-Kyu Kim proposed a plan of expanding Severance Hospital in Sinchon to have 2000 sickbeds using a financial loan from Germany and government support, as well as preferentially employing nurses who were returning home

Received: May 9, 2019

Corresponding author: Byung Soo Kim, MD, PhD, Emeritus Professor, Yonsei University College of Medicine, 50-1 Yonsei-ro, Seodaemun-gu, Seoul 03722, Korea. E-mail: kbschadr@empas.com

- The author has no potential conflicts of interest to disclose.

(C) Copyright: Yonsei University College of Medicine 2019

This is an Open Access article distributed under the terms of the Creative Commons Attribution Non-Commercial License (https://creativecommons.org/licenses/ by-nc/4.0) which permits unrestricted non-commercial use, distribution, and reproduction in any medium, provided the original work is properly cited. from Germany.

Deputy Prime Minister of EPB Duck-woo Nam said that government support was impossible, as Yonsei University Health System was a private college, and recommended him to receive a financial loan from the German government as an alternative. So he met with officials from the German government to discuss the loan issue from June 1975. German government dispatched an investigative group to survey several university hospitals with the purpose of determining the qualification of institution for acquiring a government loan.

Although Severance was selected as the most suitable institution due to its long history and management capabilities, the survey group was against the idea of newly constructing Severance Hospital in Sinchon with the help of financial loan from Germany. At that time, President Chung-hee Park was very interested in improving the medical environment and invigorating the medical industry with a financial loan from Germany. In addition, First Lady Young-soo Yuk had also taken counsel from Dr. Hyo-Kyu Kim on the issue of children's foundation she had established. Government cabinet members also respected the words of Dr. Hyo-Kyu Kim.

By 1976, the issue of German loan had slowly progressed. A loan of 15 million Deutsche Mark for the new construction of general hospital that could hold 500 sickbeds in Yeongdong area was agreed upon in a Korean-German economic ministers' conference. At that time, Yeongdong was a wild field. It was a backward region of Seoul that was home to only about 200 households. The German survey group also allowed us to construct a hospital in this area and establish a medical connection system by opening a health center in Gwangju and Yongin in Gyeonggi province, respectively.

At that time, Dr. Hyo-Kyu Kim palled around with Minister of Construction Jae-gyu Kim (1974-1976), a clansman from the same hometown who used the same generation name, Kyu. Jae-gyu Kim was a classmate of President Chung-hee Park 


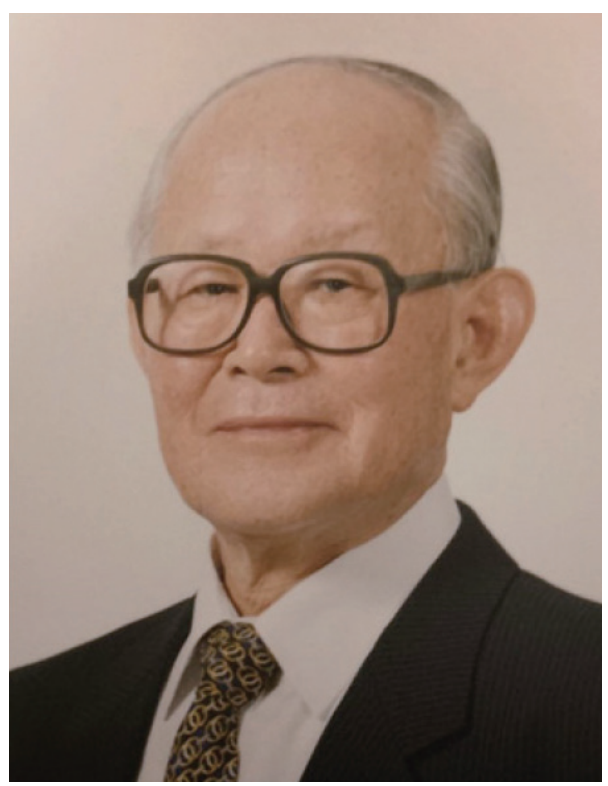

Fig. 1. A photograph of Dr. Hyo-Kyu Kim when he simultaneously served as the Vice President of Yonsei University in charge of medical affairs and the Director of the Medical System.

in the second class of Korea Military Academy. He had much influential power, and later became the director of the Korean Central Intelligence Agency (1976-1979). He later became well known for having assassinated President Chung-hee Park. Minister Jae-gyu Kim not only actively supported the new construction of a hospital in Yeongdong area by providing tips on future plan to develop Gangnam area, but also helped purchase of a $23100 \mathrm{~m}^{2}$ site at 220 million KRW, which was an exceptional price value for a site in Dogok-dong.

However, after hearing that a hospital would be constructed in a wild field, it seemed that many professors of the Health System, as well as the medical sector as a whole, were against the idea. I remember returning from the United States in 1974 and seeing what the public opinion was like at that time. Dr. Hyo-Kyu Kim overcame the difficulty with his patient personality and his ability to see into the future. As a result, both Gangnam Severance and the current Health System were able to advance.

At that time, 15 million Deutsche Mark was about 3 billion KRW, and the budget for Yonsei University Health System in 1975 was 12.4 billion KRW; therefore, borrowing such a large amount of money using an international loan was not something most people could imagine back then. The terms of a financial loan from German government were very advantageous according to the circumstances at that time, as the interest rate was $2.0 \%$ and repayment was to be made by installment over 20 years after a 10-year grace period.

Everything worked out fine with the cooperation of Prime Minister Kyu-hah Choi, Deputy Prime Minister of EPB Duckwoo Nam, and Minister of Construction Jae-gyu Kim. At that time, Dr. Hyo-Kyu Kim made desperate efforts. He visited
Germany more than 20 times to meet with German government officials and the responsible staff of Kreditanstalt für Wiederaufbau Bankengruppe, which was the bank that was supposed to provide the financial loan. Although the decision on the financial loan from Germany was made through a difficulty process, Mr. Hyun-hwak Shin, the Minister of Health and Social Affairs (1975-1978), which handled hospital licensing and medical administration at that time, started interrupting the progress after he became frustrated with the way things were being carried out by the office of Prime Minister and Economy Planning Board, excluding the office of primary concern.

The biggest reason for refusal was the fact that it was being planned to be built in Dogok-dong, Seoul, while the original plan was to build it in a rural area. As he refused to grant approval despite much persuasive efforts, Alumnus Jae-yoo Choi, who served as a General Director of Severance Hospital (1945), the Minister of Health and Social Affairs (1955-1956), the Minister of Education (1957-1960), and the Foundation Director of Yonsei University (1965-1972), was invited to persuade Minister Hyun-hwak Shin. As Minister Shin and Alumnus Jae-yoo Choi were cabinet members together at the time of April 19 revolution in 1960 and shared their fates of being jailed together for almost 2 years for undertaking political responsibilities, they had a very close relationship. As a result, he finally approved the construction of Gangnam Severance Hospital under the condition of constructing Incheon Industrial Accident Hospital and a general hospital in Yongin and Gwangju, respectively (Figs. 2-4). We now believe that it would have been better if the site of Samho Apartment, which is blocking Gangnam Severance, was also purchased at that time. However, it was impossible under the past circumstances.

Dr. Hyo-Kyu Kim graduated from First Ordinary High School (current Kyunggi High School) with flying colors during the Japanese occupation. Although most of his classmates entered Imperial University in Japan or Keijō (Gyeongseong) Imperial University, it was difficult for him to enter a national university of Japan, because his deceased father was actively involved in the dependence of Korea and was classified as a faulty Korean with impure thought. At that time, Dr. Hyo-Kyu Kim entered Severance Medical College at the suggestion of Professor Il-seon Yun of Severance Medical College, who was a classmate of his deceased father in Kyoto Imperial University. Dr. HyoKyu Kim graduated in 1941.

After graduation, he majored in pediatrics under Professor Izumi of Keijō Imperial University Hospital through strong recommendation by Dr. Moon-hyung Eom, a senior from his hometown who graduated from Keijō Imperial University. He finished his major course of pediatrics in 1945 when Korea was freed from Japanese colonial rule. Dr. Hyo-Kyu Kim opened a big pediatric hospital in Daesin-dong in central Busan, and made a lot of money. Dr. Hyo-Kyu Kim was a person who was particularly faithful to his teachers and colleagues. During the 


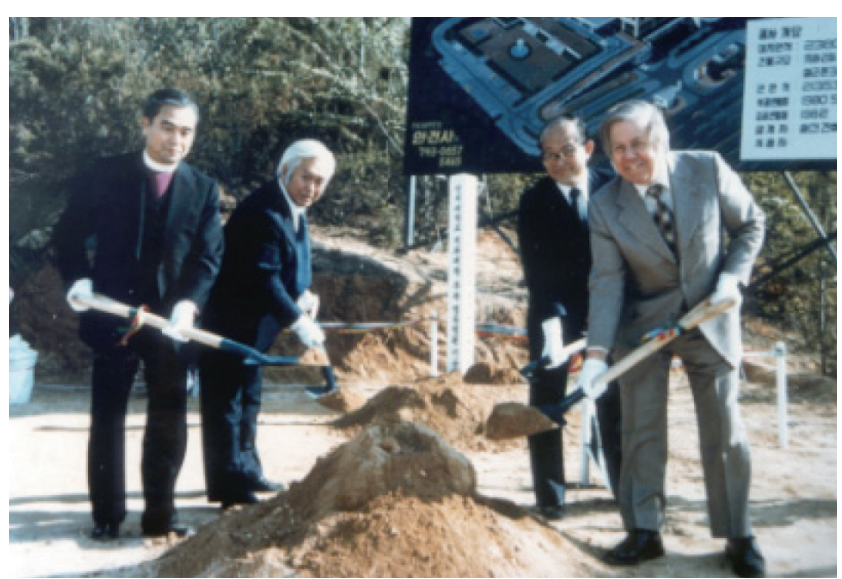

Fig. 2. A group photograph taken at the groundbreaking ceremony of the hospital (May 16, 1980).

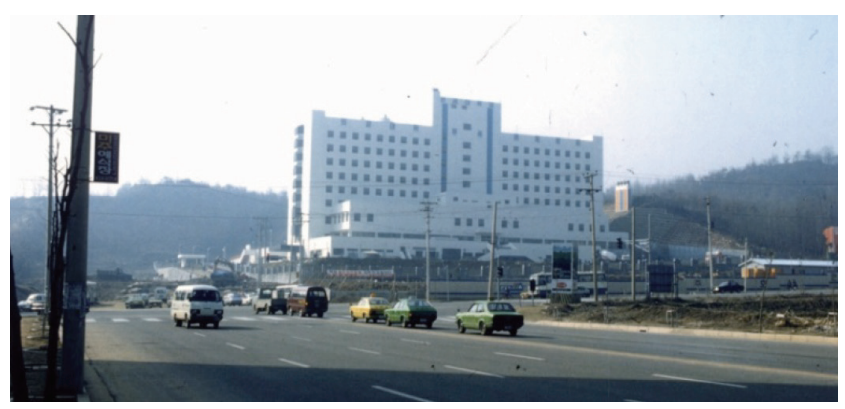

Fig. 3. A photo of the main building of Gangnam Severance (former Yeongdong Severance) after it was completed.

Korean War, Severance professors fled to Busan and opened Severance Hospital in Geoje Island to give medical treatment to evacuees, in the course of which Dean Myung-Sun Kim and many Severance alumni received much help from Dr. HyoKyu Kim staying in the hospital. From 1951, he served as an army surgeon for six years. After that, Dr. Jae-yoo Choi, who had served as the chief attending doctor of President Seungman Lee, accepted the post as the vice president of Ewha Woman's University at the request of President Helen Kim of Ewha Woman's University with a plan to open Ewha Medical College. Dr. Hyo-Kyu Kim was invited to serve as the head professor of pediatric department at Ewha Medical College.

As Dr. Hyo-Kyu Kim successfully operated the pediatric department and his excellent management ability was also acknowledged, he was appointed as the director of Ewha Woman's University Medical Center in 1959, after two years of becoming the head professor. He greatly contributed to the advancement of Ewha Woman's University Dongdaemun Hospital. When he was the director of Ewha Woman's University Dongdaemun Hospital and head professor of pediatric class at the same time, he was also elected as the chairman of the Korean Pediatric Society. Dr. Hyo-Kyu Kim resigned from Ewha Medical College and opened Seoul Hospital, which was the first group practice hospital jointly operated by several famous professors, in 1964. As he was modest and kind by na-

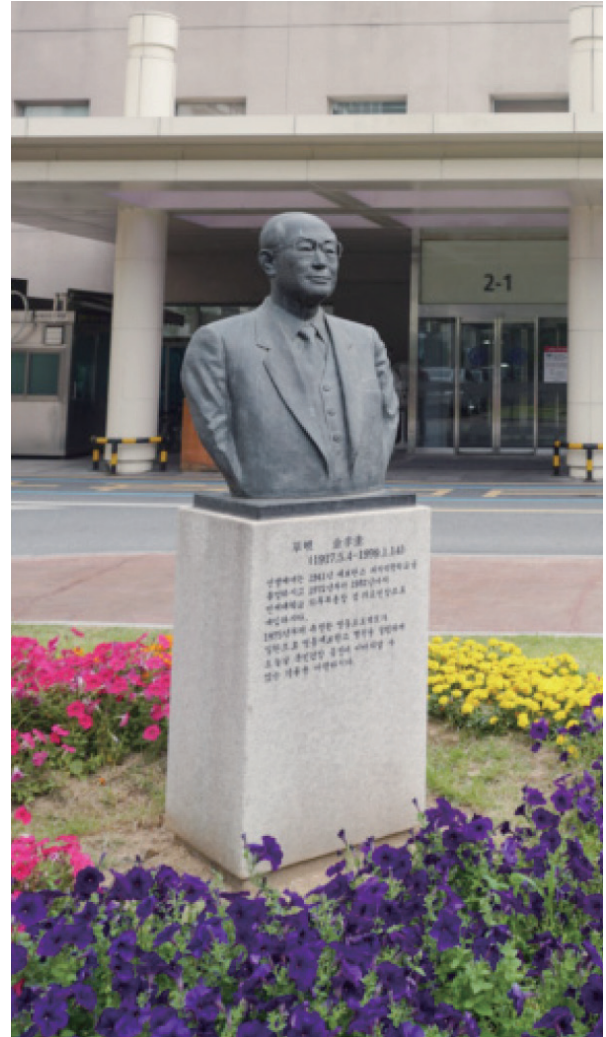

Fig. 4. A bust of Dr. Hyo-Kyu Kim located in Gangnam Severance Hospital.

ture and provided treatments to children and parents without asserting authority, despite his renowned status as the head professor of pediatric department, the hospital was thronged with children not only from Seoul but also from all over the country, leading to great success.

In February 1971, when Seoul Hospital was highly prosperous, he was elected as the chairman of the Severance Alumni association. Before that, he was relatively an outsider after he left Severance or after his graduation. At that time, Severance Hospital was experiencing some business difficulties, as the location was in a suburban area after it was relocated in Sinchon. It was going through a slump as it was focusing on maintenance of the status quo relying on old custom and the brand name of Severance. Severance Alumni Association was little more than a name with absolutely no role in or contribution to Yonsei University Medical System, the alma mater, and the existence itself fell into mannerism of being satisfied with opening a regular general assembly meeting once a year. The only positive thing about the hospital was that patients from Yeongdeungpo and Incheon areas were easily able to visit the hospital via the Second Han River Bridge (current Yanghwa Bridge) opened by President Chung-hee Park's administration.

Immediately after he was inaugurated as the chairman of the Severance Alumni Association, Dr. Hyo-Kyu Kim came up with new creative tasks and started putting them into practice, as he usually did. The first thing he promoted was the establishment of a system for regular publishing of new alumnae 
bulletins to be distributed to the alumni in order to bring together their power to reform Severance, which was in the mire of stagnation. By publishing bulletins with faithful contents, he hoped to rekindle the alumni's interest in their alma mater.

Next, he decided to raise funds from the alumni, for the first time in the long history of Severance, for constructing a dormitory (Jejunghaksa) which would make superior students from all over the nation and the members of the graduating classes devote themselves more to their studies, and also become a place where the spirit of Severance would be inherited. The will of Dr. Hyo-Kyu Kim, the Chairman of Alumni Association, was supported wholeheartedly by Dr. Myung-Sun Kim. In order to raise funds, Dr. Hyo-Kyu Kim himself not only devoted his time to visiting alumni who were located all over Korea, but he also visited other alumni who were living in different cities in the United States at his own expense to help advance the USA Alumni Association.

I, the author, also organized Boston Severance Alumni Association and had regular meetings during the period I studied there. When Dr. Hyo-Kyu Kim visited Boston with Dr. Myung-Sun Kim in 1971, I raised US \$2000 and remitted the funds to him.

At that time, our fundraising goal for the construction of Jejunghaksa was 100 million KRW. The site of Jejunghaksa, which is about $3306 \mathrm{~m}^{2}$ in size, was provided by Yonsei University. Dr. Myung-Sun Kim was a great teacher who was widely respected by all graduates as a spiritual leader of Severance at that time. He played a significant role to in making fundraising successful. Dr. Hyo-Kyu Kim was grateful to Dr. Myung-Sun Kim at all times. After a great deal of efforts, the groundbreaking ceremony for Jejunghaksa was held in May 1972, and a dedication ceremony was held in October 1974. About half of the raised funds was covered by overseas alum$\mathrm{ni}$, and the remaining half was covered by domestic alumni.

As the chairman of Alumni Association, Dr. Hyo-Kyu Kim was a pioneer of new history. His unique resolution, humbleness, and creative leadership enabled him to successfully complete various works. These characteristics were grown through Dr. Kim's personal hardships and difficult political environment of Korea while he was out of Severance for 30 years. He definitely stood out. These gave young professors, who wanted reform of their alma mater, a belief that he would become the center figure in the new Severance reform, which became the most important turning point in Dr. Hyo-Kyu Kim's life.

As the five-year economic development plan powerfully promoted by President Chung-hee Park became successful, Korea was advancing to the point where the problem of public welfare was getting resolved. The society overcame poverty and starvation. In addition, the amount of Korean export reached 1 billion US dollars. These dynamic changes in the Korean society made all institutions, including Seoul National University Hospital, to proceed with the construction of modern hospitals using financial aid from the government. As the administrative operation system of Severance, which was satisfied with the old tradition of introducing modern medicine and conducting medical education for the first time in Korea, faced financial crisis and failed to show changes and new visions in response to this, complaints toward senior professors and the head of administration were on the verge of explosion. Young professor groups, residents, and even the students openly called for school reform.

At that time, Dr. Dae Seon Park, the President of Yonsei University (1964-1975), perceived school ambience overflowing with complaints of Severance members and financial crisis of the hospital. President Dae Seon Park, who had highly valued the personality of Dr. Hyo-Kyu Kim as well as his management ability of having achieved a new history as the chairman of the Alumni Association and his vision, carried out a shocking appointment that no one had expected. In September 1972, Severance Alumni Association Chairman Hyo-Kyu Kim, who was 55 years old, was appointed as the vice president to be in charge of medical affairs, and Professor Jae-Mo Yang was appointed as the dean of the Medical College, as his ability was greatly acknowledged. Another action was also taken to let the vice president take charge of medical affairs as the director of Severance Hospital at the same time, as business administration became difficult. In the course of this, President Dae Seon Park was said to have experienced deep agony as an university president who was a theologian with no perfect understanding of the Yonsei University Health System.

The reform led by Vice President Hyo-Kyu Kim in cooperation with Dean Jae-Mo Yang was not only focused on head professor meeting that held all decision-making rights, but also on changing and adjusting all administrative systems. During this time, the system of life-long head professor was changed. The current system, which allows consecutive terms of four to six years, started at that time.

Also, the only time that opinions of all professors were collected was at the faculty meeting in its entirety. Since it was difficult to converge opinions because the organization itself was too big, standing faculty meetings, organized by selecting a representative professor in each rank, were established to let them make decisions on matters related to personnel, budget, academic affairs, and other important topics. He settled transparent management environment by executing personnel right, allotment of reimbursement for department operating cost, and even allotment of charge for selective care which were the rights of life-long head professors in accordance with the regulation.

The second big achievement was the major innovation of education course. By installing an education reform committee, he set up a modern education course that is being executed to this day.

As Vice President Hyo-Kyu Kim achieved great things such as continuous advancement of the Medical System, establishment of Gangnam Severance Hospital, establishment of 
Graduate School of Public Health, Yonsei University, integration of Wonju Christian Hospital Foundation, and establishment of Wonju Medical College, he served as the vice president of Yonsei University and director of the Yonsei University Health System for 10 years (1972-1982), in five consecutive terms, leaving a significant mark in the history of Yonsei University Health System. After retiring, he established the Daewoo Medical Foundation at the request of Chairman Woojung Kim of Daewoo Group. He then served as the chairman of the board and contributed to ensuring successful return of corporate profit of Daewoo Group to the Korean society. Also, after Chairman Woo-jung Kim took over Ajou University that was undergoing financial difficulty at the time, Dr. Hyo-Kyu Kim was invited to serve as the University president. He not only established the medical college and university hospital there, but also fostered Ajou University as the current firstclass university over the 10-year period he served as president (1985-1995).

After seeing me when I was working as a cancer specialist at Harvard, Dr. Hyo-Kyu Kim decided to grant me special employment after discussing the matter with President Dae Seon Park. So I returned to Korea in 1974, and then dedicated my whole life to working at the Yonsei Cancer Center. This was to his credit. Dr. Hyo-Kyu Kim thought it was nice of him to do so, and I am always thankful to him. When he was living in Hyangrin-dong, Yongin after his retirement, he said he was so proud to see me serving as the president of Yonsei University. He gave me some important words of wisdom and encouragement that I will remember for the rest of my life.

The recollection of Dr. Kim's entire life was told verbally. It was also left in writing when he was alive. Such records help us understand his life philosophy and perspective of looking at the world, and those are the words that his followers should bear in mind. Dr. Kim said that the world is perilous and that a person's mind is a rope of sand, referring to the following Chinese idiom: “A person's mind is more perilous than river waters, and compassion is thinner than ice in spring (江潮險人心 更險 春水薄 仁情更薄).” He also said that the direction and quality of people's lives vary depending on how well the person in charge of an organization knows it, endures it, and copes with it properly. Also, Dr. Hyo-Kyu Kim deplored that youngsters only cling to the phenomena and pleasure right in front of them, and that many people do not try to understand the world or lead their lives with fresh dream, apparent objective, or passion. Dr. Hyo-Kyu Kim said that the administrative manager of a college should be honest above all else because, if the administrative manager's mind is contaminated with greed for honor and money, the college will lose its function, stop advancing, and face a crisis. He also said that a college that has lost the function of participation and criticism will lose creativity. Lastly, he warned us that a person who easily compromises with the reality, one who has knowledge not accompanied by dignity, and one who practices science not accompanied by humanity will be ruined in the end.

The great teachers and leaders from our alma mater include Dr. Avison, Mr. Severance, Dr. Kung Sun Oh, and Dr. MyungSun Kim. Since I think of Dr. Hyo-Kyu Kim as a teacher who inherited the outstanding spirits of these teachers and leaders, I write this wholeheartedly to leave a small mark of his great achievements in history. 